\title{
1 Timing of exposure is critical in a highly sensitive model of SARS-CoV-2 transmission
}

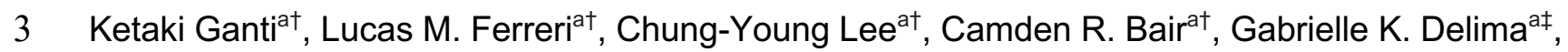

4 Kate E. Holmes ${ }^{a \ddagger}$, Mehul S. Suthar ${ }^{a, b, c, d}$, and Anice C. Lowen ${ }^{a, d *}$

6 a Department of Microbiology and Immunology, Emory University School of Medicine, Atlanta, GA,

$7 \quad 30322$

$8{ }^{b}$ Emory Vaccine Center, Emory University School of Medicine, Atlanta, GA, 30322

$9{ }^{c}$ Center for Childhood Infections and Vaccines of Children's Healthcare of Atlanta, Department of

10 Pediatrics, Emory University School of Medicine, Atlanta, GA, USA.

$11{ }^{d}$ Emory-UGA Center of Excellence for Influenza Research and Surveillance (CEIRS), Atlanta, GA,

$12 \quad 30322$

13

14 These individuals contributed equally to the research presented.

15 TThese individuals contributed equally to the research presented.

16 *Address correspondence: anice.lowen@emory.edu 


\section{Abstract}

18 Transmission efficiency is a critical factor determining the size of an outbreak of infectious

19 disease. Indeed, the propensity of SARS-CoV-2 to transmit among humans precipitated and

20 continues to sustain the COVID-19 pandemic. Nevertheless, the number of new cases among

21 contacts is highly variable and underlying reasons for wide-ranging transmission outcomes

22 remain unclear. Here, we evaluated viral spread in golden Syrian hamsters to define the impact

23 of temporal and environmental conditions on the efficiency of SARS-CoV-2 transmission through

24 the air. Our data show that exposure periods as brief as one hour are sufficient to support robust

25 transmission. However, the timing after infection is critical for transmission success, with the

26 highest frequency of transmission to contacts occurring at times of peak viral load in the donor

27 animals. Relative humidity and temperature had no detectable impact on transmission when

28 exposures were carried out with optimal timing. However, contrary to expectation, trends

29 observed with sub-optimal exposure timing suggest improved transmission at high relative

30 humidity or high temperature. In sum, among the conditions tested, our data reveal the timing of

31 exposure to be the strongest determinant of SARS-CoV-2 transmission success and implicate

32 viral load as an important driver of transmission. 


\section{Introduction}

35 The COVID-19 pandemic has led to a public health emergency and social disruption on a scale

36 not seen since the influenza pandemic of 1918. Non-pharmaceutical interventions have been

37 pursued in many parts of the world with the goal of limiting the impact of the outbreak (1-3). These

38 interventions seek to interrupt transmission of the virus (1-3). Effective use of non-pharmaceutical

39 interventions therefore relies heavily on fundamental understanding of SARS-CoV-2 transmission

40 and the viral, host, and environmental factors that modulate its efficiency.

42 For example, efforts to contain viral spread through contract tracing rely on estimates of the

43 duration of exposure needed to support transmission. In defining a close contact, exposure to an

44 infected individual for a minimum of 15 or 30 minutes is often used $(4,5)$. In turn, quarantine

45 measures for those identified as a close contacts rely on estimates of incubation period,

46 commonly reported as 10-14 days $(6,7)$. Similarly, policies for isolation of positive cases reflect

47 the potential for onward transmission within a period up to 10 or 14 days post-infection $(6,7)$.

48 Evidence-based refinement of these definitions is important for establishing infection-control

49 practices that minimize risk of transmission while also mitigating the social and economic burden

50 of quarantine measures.

52 Much attention has also been paid to the potential for various environmental conditions to

53 modulate the efficiency of transmission. Epidemiological investigation of environmental

54 parameters has returned varied results (8-10). Low temperature was found to be associated with

55 increased SARS-CoV-2 transmission in some cases $(11,12)$ but not others $(13,14)$. Similarly,

56 dry conditions were found to be favorable for SARS-CoV-2 spread in a subset of studies $(12,15)$.

57 In general, detected effects of temperature and humidity on reproduction number or epidemic

58 growth were dwarfed by those of active interventions such as restrictions on mass gatherings (14,

59 16, 17). Indeed, the complexity of conditions under which human exposures occur, and 
60 incomplete information regarding those conditions, can frustrate efforts to define parameters

61 important for transmission efficiency. Examination of transmission in relevant experimental

62 models therefore forms an invaluable complement to epidemiology.

64 Golden Syrian hamsters are highly susceptible to infection with SARS-CoV-2, show clear signs

65 of disease, shed the virus at high titers from the upper respiratory tract, and transmit SARS-CoV-

662 to direct contacts and through the air (18-20). This model species has been used to evaluate

67 the utility of vaccines, drugs, and passively transferred antibodies for blocking transmission (20-

68 22). Nevertheless, an important limitation of the model is that its extreme permissiveness can

69 interfere with the detection of differences in transmission efficiency. To date, analysis of the fitness

70 of novel variants has relied on their co-infection with ancestral strains (23-25). While sensitive,

71 this approach introduces the likelihood of viral fitness being modulated by interactions between

72 the co-infecting viruses $(26,27)$. There is therefore a need for refinement of the hamster model

73 to increase the stringency of transmission. Identification of temporal and environmental factors

74 that modulate transmission can help to achieve this goal.

76 Here, we used a hamster model to investigate the impact of a range of temporal and 77 environmental conditions on SARS-CoV-2 transmission. Our data indicate that high transmission 78 efficiency is maintained with exposure durations as short as one hour and across a wide range of 79 humidity and temperature conditions. Conversely, the timing of exposure relative to infection of 80 donor animals was found to strongly modulate transmission, with exposure prior to $16 \mathrm{~h}$ and after 8148 hours post-inoculation (hpi) yielding little or no spread to contacts. The temporal structure of 82 transmission corresponded with infectious viral titers in the nasal tract, strongly suggesting that 83 the infectious period is defined by the dynamics of viral load in donor hosts. 


\section{Results}

\section{Minimal impact of exposure duration on SARS-CoV-2 transmission}

88 Reasoning that viral densities in the air or the recipient respiratory tract may accumulate over

89 time, we hypothesized that the period of time during which naïve animals are exposed to the

90 exhaled breath of infected animals would impact the efficiency of transmission. To test this

91 hypothesis, we used an exposure system in which naïve hamsters are placed on the opposite

92 side of a porous, double-walled, barrier from infected hamsters for a defined duration

93 (Supplementary Figure 1). Exposures were carried out under controlled environmental

94 conditions at 24 hpi of donor animals for periods of $5 \mathrm{~d}, 8 \mathrm{~h}, 4 \mathrm{~h}$ and $1 \mathrm{~h}$. After exposure, animals

95 were singly housed. Collection of nasal lavage samples was used to monitor for transmission.

96 The results revealed robust transmission for all exposure durations tested (Figure 1). Positivity in

97 a subset of contact animals was detected at the first sampling time of $2 \mathrm{~d}$ post-inoculation ( $1 \mathrm{~d}$

98 post-exposure) and all contact animals were found to harbor infectious virus by $8 \mathrm{~d}$ post-

99 inoculation (7 d post-exposure). The period of exposure did not give rise to clear temporal trends

100 in transmission. Thus, within the range tested, the period of exposure had minimal impact on

101 SARS-CoV-2 transmission in hamsters. The data indicate that a minimal infectious dose is readily

102 transferred to recipient hamsters within the course of one hour.

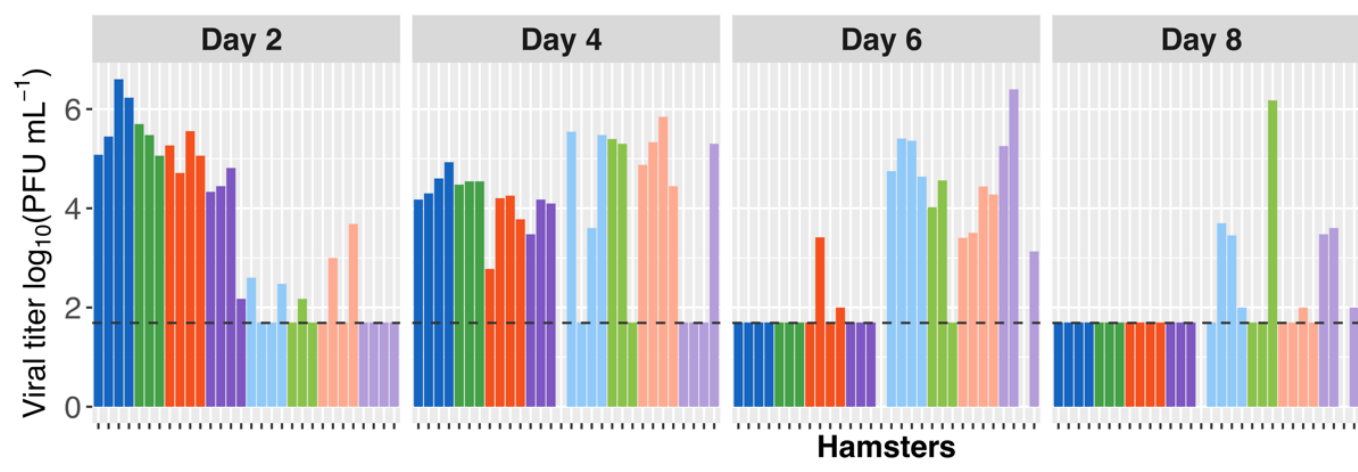

Inoculated Exposed

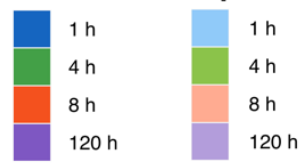

Transmission

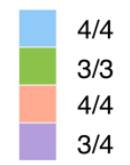

$4 / 4$

$3 / 4$

103

104 Figure 1. Exposure durations as short as $1 \mathrm{~h}$ are sufficient for robust SARS-CoV-2

105 transmission. Viral titers in nasal lavage samples collected from inoculated (dark colors) and 
exposed (light colors) hamsters are plotted. Facets show results from 2, 4, 6 and 8 days postinoculation (dpi) with different colors indicating the duration of exposure. Animals were inoculated with $1 \times 10^{4}$ PFU (titered on VeroE6 cells) and exposures initiated at 24 hpi. Exposures were carried out for five days at $30^{\circ} \mathrm{C}$ and $50 \% \mathrm{RH}$. Horizontal dashed line indicates limit of detection

110 (50 PFU). Missing data indicate that the animal died or was euthanized mid-way through the 111 experiment. The fraction of transmission pairs in which recipients shed infectious virus at one or 112 more time points is indicated at the right.

\section{Timing of exposure strongly modulates SARS-CoV-2 transmission}

115 We next tested the impact of the timing of exposure on SARS-CoV-2 transmission. To test for 116 transmission at early times, brief exposures of one or two hours were carried out at $10-12,12-$

$11714,14-16,16-17$ or 24-25 hpi. Similarly, to evaluate transmission potential late in the course of 118 infection, exposures were carried out for two hours on days 2, 4 and 6 post-inoculation. Nasal 119 lavage samples collected from donor animals at the conclusion of each exposure window were used to assess viral loads at the time of exposure, while serial samples collected from these same 121 donors across multiple time points were used to evaluate the dynamics of viral load.

123 Analysis of nasal viral load in donor animals sampled at the time of exposure revealed a sharp

124 increase between $12 \mathrm{~h}$ and $25 \mathrm{hpi}$, from an average of less than $1 \times 10^{3} \mathrm{PFU} / \mathrm{ml}$ at $12 \mathrm{~h}$ to 125 approximately $1 \times 10^{7} \mathrm{PFU} / \mathrm{ml}$ at $25 \mathrm{~h}$. Loads then declined over 2, 4 and 6 days post-inoculation 126 (dpi), averaging about $1 \times 10^{6} \mathrm{PFU} / \mathrm{ml}$ on day 2 and declining to $<1 \times 10^{2} \mathrm{PFU} / \mathrm{ml}$ by day 6 (Figure 127 2A). Dynamics of viral load across all inoculated animals sampled on days 2, 4, 6 and 8 were 128 consistent with these results obtained at the conclusion of specific exposures and revealed that 129 titers were typically below the limit of detection by 8 dpi (Supplementary Figure 2). Taken 130 together, the results show high viral loads of $1 \times 10^{5}-1 \times 10^{7} \mathrm{PFU} / \mathrm{ml}$ are reached by $17 \mathrm{~h}$ and 131 sustained at $48 \mathrm{hpi}$, but that titers fall below this range by $4 \mathrm{dpi}$. 
133 Analysis of exposed animals revealed a strong impact of the timing of exposure on transmission

134 (Figure 2B). Naïve animals exposed for $2 \mathrm{~h}$ beginning at 10, 12 or $14 \mathrm{hpi}$ of donors were not 135 infected. By contrast, transmission was seen in two of four animals exposed for $1 \mathrm{~h}$ beginning at

$13616 \mathrm{hpi}$ and all four animals exposed for $1 \mathrm{~h}$ beginning at $24 \mathrm{hpi}$. Exposure at late time points 137 showed appreciable transmission only on day 2 post-inoculation, with five of eight hamsters

138 contracting infection when exposed for $2 \mathrm{~h}$ beginning at $2 \mathrm{dpi}$. Overall, the data reveal a window 139 of transmissibility from $17 \mathrm{~h}$ to $2 \mathrm{~d}$ after infection of the donor hamster (Figure 2C).

140

141 To test whether viral load is a likely determinant of infectious period, nasal lavage titers in donor

142 animals at the conclusion of exposure were evaluated. Significantly higher viral loads were 143 detected in hamsters that transmitted to contacts, compared to those that did not transmit SARS-

\section{CoV-2 (Figure 3).}


A

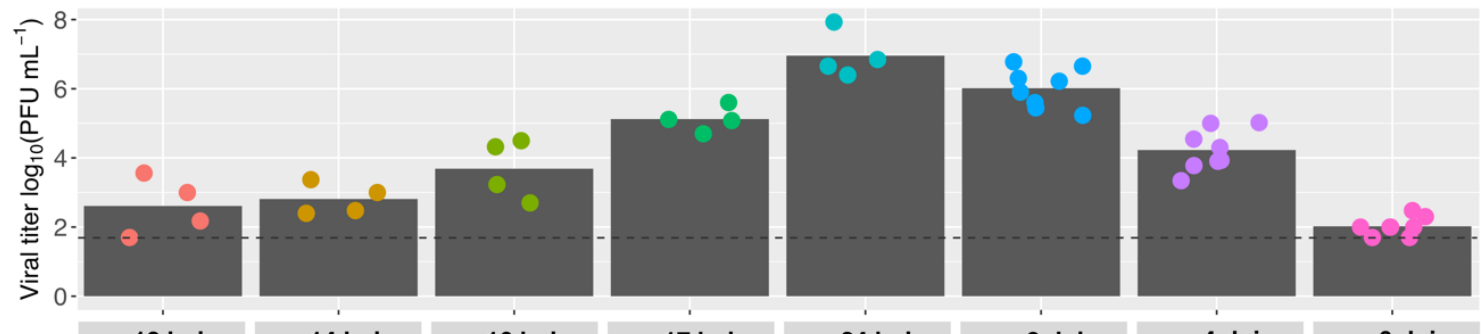

B
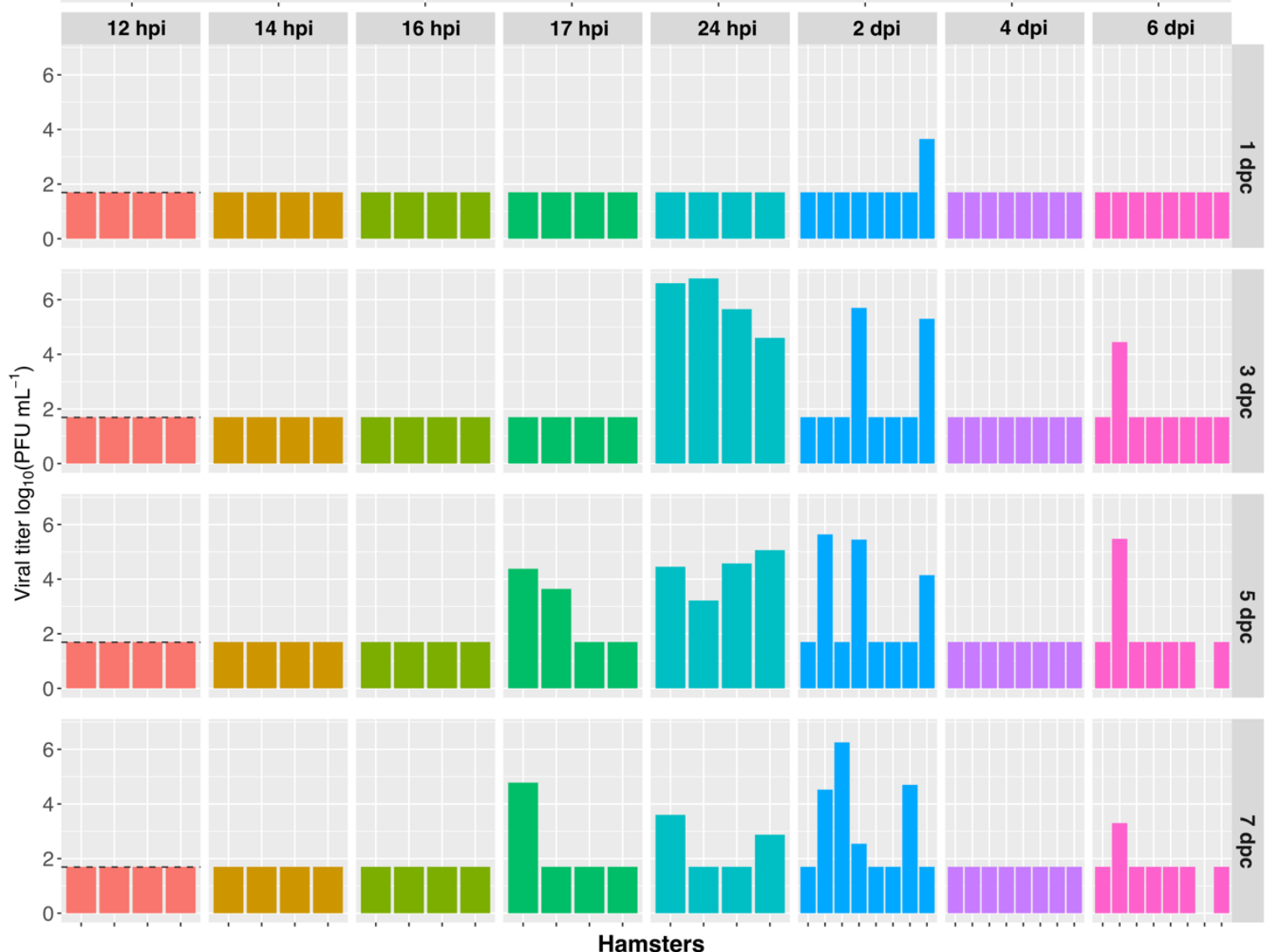

Hamsters

C

Transmission

\begin{tabular}{|c|c|c|c|c|c|c|c|}
\hline $\mathbf{1 2} \mathbf{h p i}$ & $\mathbf{1 4} \mathbf{h p i}$ & $\mathbf{1 6} \mathbf{h p i}$ & $\mathbf{1 7} \mathbf{h p i}$ & $\mathbf{2 4} \mathbf{h p i}$ & $\mathbf{2 ~ d p i}$ & $\mathbf{4} \mathbf{d p i}$ & $\mathbf{6 ~ d p i}$ \\
\hline $0 / 4$ & $0 / 4$ & $0 / 4$ & $2 / 4$ & $4 / 4$ & $5 / 8$ & $0 / 8$ & $1 / 8$ \\
\hline
\end{tabular}

147 Figure 2. Period of transmissibility corresponds to period of high viral load in donor

148 animals. A) Viral load in inoculated animals at the conclusion of the exposure period. Time points

149 are indicated under the $x$-axis and a different color is assigned to each different exposure period.

150 Bars show mean viral titer and dots show individual hamsters. B) Viral titers in nasal washes

151 collected from contacts. Different exposure periods are shown with different colors. The time post- 
152 inoculation at which the exposure period concluded is shown at the top of each facet. Time points

153 at which nasal wash samples were collected are shown at the right of each row in units of days

154 post contact (dpc). For the early exposure groups, $n=4$ transmission pairs. For the 2 dpi, 4 dpi

155 and 6 dpi exposure groups, data from two independent experiments are displayed together giving

156 total $n=8$ transmission pairs. All animals were inoculated with $1 \times 10^{2}$ PFU (titered on VeroE6 cells)

157 and exposures were carried out at $20^{\circ} \mathrm{C}$ and $50 \% \mathrm{RH}$. Horizontal dashed line indicates limit of

158 detection (50 PFU). Missing data indicate that the animal died or was euthanized mid-way through

159 the experiment. C) The fraction of transmission pairs in which recipients shed infectious virus at 160 one or more time points is indicated.

161

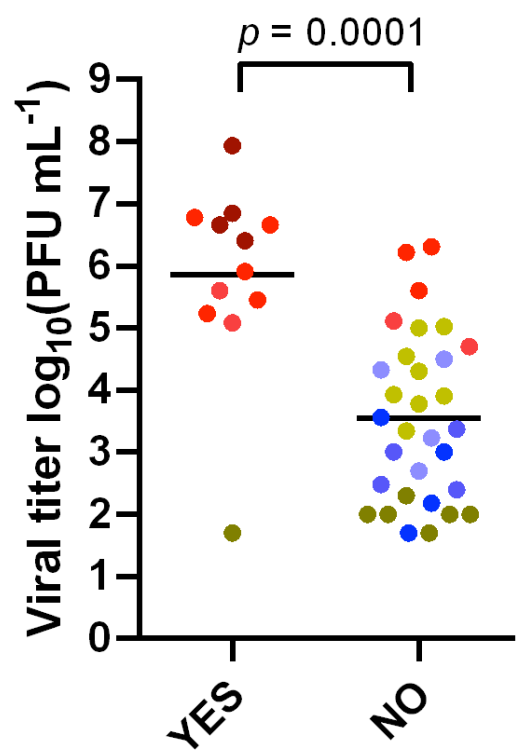

Time of exposure (hpi)

\section{Transmission}

162 Figure 3. Transmission is associated with higher donor viral loads. Data analyzed are also

163 shown in Figure 2. Viral titers detected in nasal lavage samples of donor animals collected at the

164 time of exposure are plotted according to whether transmission occurred or not. All animals were

165 inoculated with $1 \times 10^{2} \mathrm{PFU}$ (titered on VeroE6 cells) and exposures were carried out at $20^{\circ} \mathrm{C}$ and

$16650 \% \mathrm{RH}$. The time of exposure in hours post-inoculation (hpi) is shown in different colors.

167 Unpaired Student's t-test was performed on log-transformed data. 


\section{Minimal impact of humidity on SARS-CoV-2 transmission}

170 Ambient humidity is known to modulate the efficiency of aerosol transmission of influenza A virus, 171 with dry conditions favoring spread (28-30). We hypothesized that a similar effect would be

172 detectable for SARS-CoV-2 and therefore evaluated transmission with exposures carried out 173 under dry $(20$ or $30 \% \mathrm{RH})$, intermediate $(50 \% \mathrm{RH})$ or humid $(80 \% \mathrm{RH})$ conditions. In each case,

174 temperature was held constant at $20^{\circ} \mathrm{C}$. When a five day exposure duration beginning at $24 \mathrm{hpi}$

175 was used, transmission was found to be highly efficient irrespective of humidity (Figure 4A).

176 Reasoning that any effects of humidity may be difficult to detect when overall transmission

177 efficiencies are saturated, we performed similar experiments with exposures carried out early 178 after infection when intermediate transmission frequency was observed. Namely, naïve animals 179 were exposed for three hours beginning at $14 \mathrm{~h}$ after inoculation of donors. Since placement of 180 the hamsters disrupts the relative humidity in their environment, this timing allowed equilibration 181 of relative humidity during a period when no transmission was observed (14-16 hpi; Figure 2B). 182 Here, results revealed a trend of more transmission under high RH conditions (Figure 4B). These 183 results clearly indicated that, contrary to expectation, low ambient humidity was not favorable for

184 transmission. However, hamsters were subjected to humidity set points for only a brief period, 185 during exposure. If the effects of humidity on transmission act at the level of the host, then they 186 would be unlikely to be manifested in this experimental system. To address this possibility, we 187 tested whether pre-conditioning of animals under different humidity conditions for $4 \mathrm{~d}$ prior to 188 inoculation or exposure impacted transmission. For a given group of hamsters, pre-conditioning 189 and exposure were carried out under the same dry, intermediate or humid conditions. Again, the 190 most transmission was seen at high $\mathrm{RH}$ (Figure 4C). These results suggest that high ambient $\mathrm{RH}$ 191 may support SARS-CoV-2 transmission in this model and indicate that low RH does not promote 192 transmission in this system. 
A

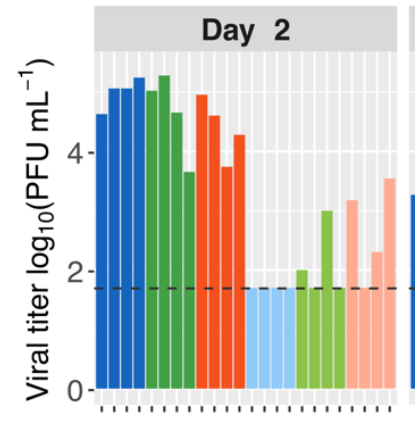

B

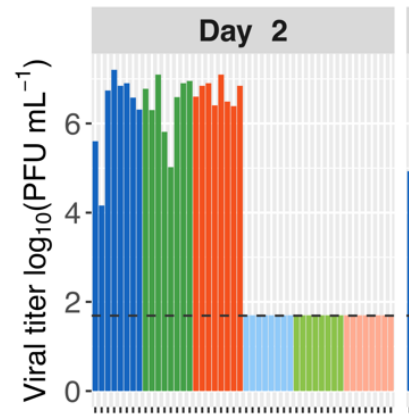

C

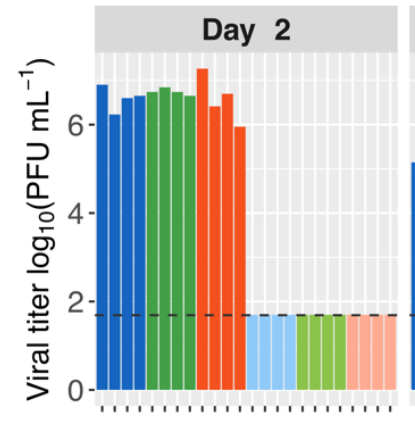

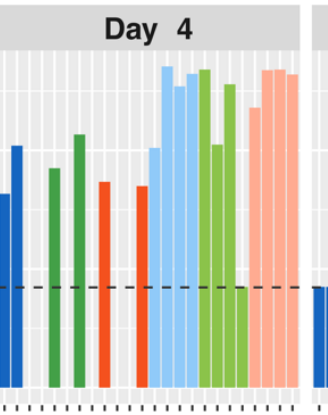

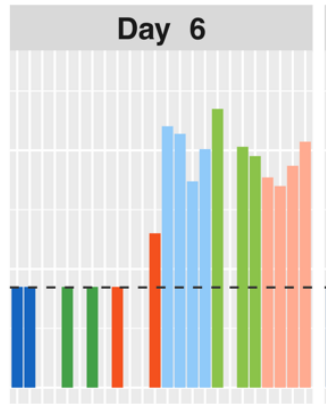

Hamsters

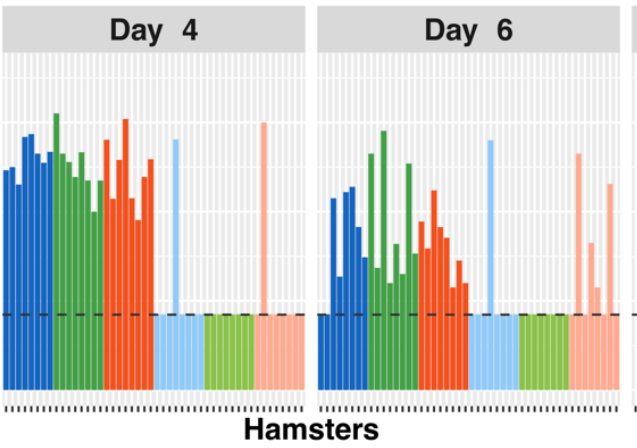

Day 4

Day 6

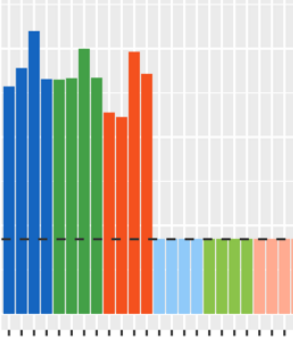

Hamsters
Day 8

Day 8

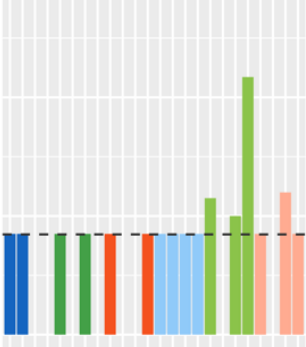

Day 8
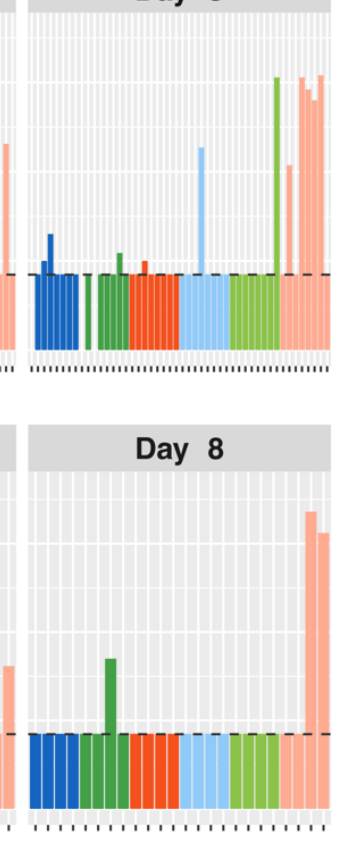

$\mathrm{RH}$ at exposure Inoculated Exposed $30 \quad 30$ $50 \quad 50$ $80 \quad 80$

Transmission
$0 / 4$
$0 / 4$
$2 / 4$

Figure 4. Low humidity does not promote SARS-CoV-2 transmission in hamsters. Viral titers in nasal lavage samples collected from inoculated (dark colors) and exposed (light colors) hamsters are plotted. Facets show results from 2, 4, 6 and 8 days post-inoculation (dpi) with different colors indicating the $\mathrm{RH}$ of exposure. A) Donor animals were inoculated with $1 \times 10^{4} \mathrm{PFU}$ (titered on VeroE6 cells) and contacts were exposed for a period five days under the indicated $R H$ conditions, beginning at 24 hpi. $N=4$ transmission pairs. B) Donor animals were inoculated with $1 \times 10^{2}$ PFU (titered on VeroE6 cells) and contacts were exposed for a period of $3 \mathrm{~h}$ under the 201 indicated RH conditions, beginning at $14 \mathrm{hpi}$. Data are combined from two independent 
202 experiments, giving a total of $n=8$ transmission pairs. C) Donor and contact hamsters were 203 preconditioned to the tested environmental $\mathrm{RH}$ for a period of four days. Donor animals were

204 then inoculated with $1 \times 10^{2}$ PFU (titered on VeroE6 cells) and contacts were exposed for a period $2053 \mathrm{~h}$ under the indicated $\mathrm{RH}$ conditions, beginning at $14 \mathrm{hpi} . \mathrm{N}=4$ transmission pairs. Horizontal 206 dashed line indicates limit of detection (50 PFU). Missing data indicate that the animal died or 207 was euthanized mid-way through the experiment. Temperature was $20^{\circ} \mathrm{C}$ in all experiments 208 shown.

210 Minimal impact of temperature on SARS-CoV-2 transmission

211 As for $\mathrm{RH}$, ambient temperature was previously found to modulate the efficiency of aerosol

212 transmission of influenza A virus, with cold conditions favoring spread (28-30). We hypothesized

213 that a similar effect would be detectable for SARS-CoV-2 and therefore evaluated transmission

214 with exposures carried out under cold $\left(5^{\circ} \mathrm{C}\right)$, intermediate $\left(20^{\circ} \mathrm{C}\right)$ or warm $\left(30^{\circ} \mathrm{C}\right)$ conditions. In

215 each case, $\mathrm{RH}$ was held constant at $50 \%$. When a five-day exposure duration beginning at $24 \mathrm{hpi}$

216 was used to compare $20^{\circ} \mathrm{C}$ and $30^{\circ} \mathrm{C}$ environments, transmission was found to be highly efficient

217 under both conditions (Figure 5A). Since our hypothesis was that cold conditions would be

218 favorable, we did not test $5^{\circ} \mathrm{C}$ in this system. Instead, we performed similar experiments with a 219 one-hour exposure beginning at $16 \mathrm{hpi}$ - an approach designed to yield intermediate levels of 220 transmission and thereby allow detection of temperature effects. While intermediate levels of 221 transmission were observed at $20^{\circ} \mathrm{C}$ and $30^{\circ} \mathrm{C}$ in these experiments, no transmission was 222 observed at $5^{\circ} \mathrm{C}$. Thus, results did not support the hypothesis that cold conditions augment 223 transmission of SARS-CoV-2 (Figure 5B). 


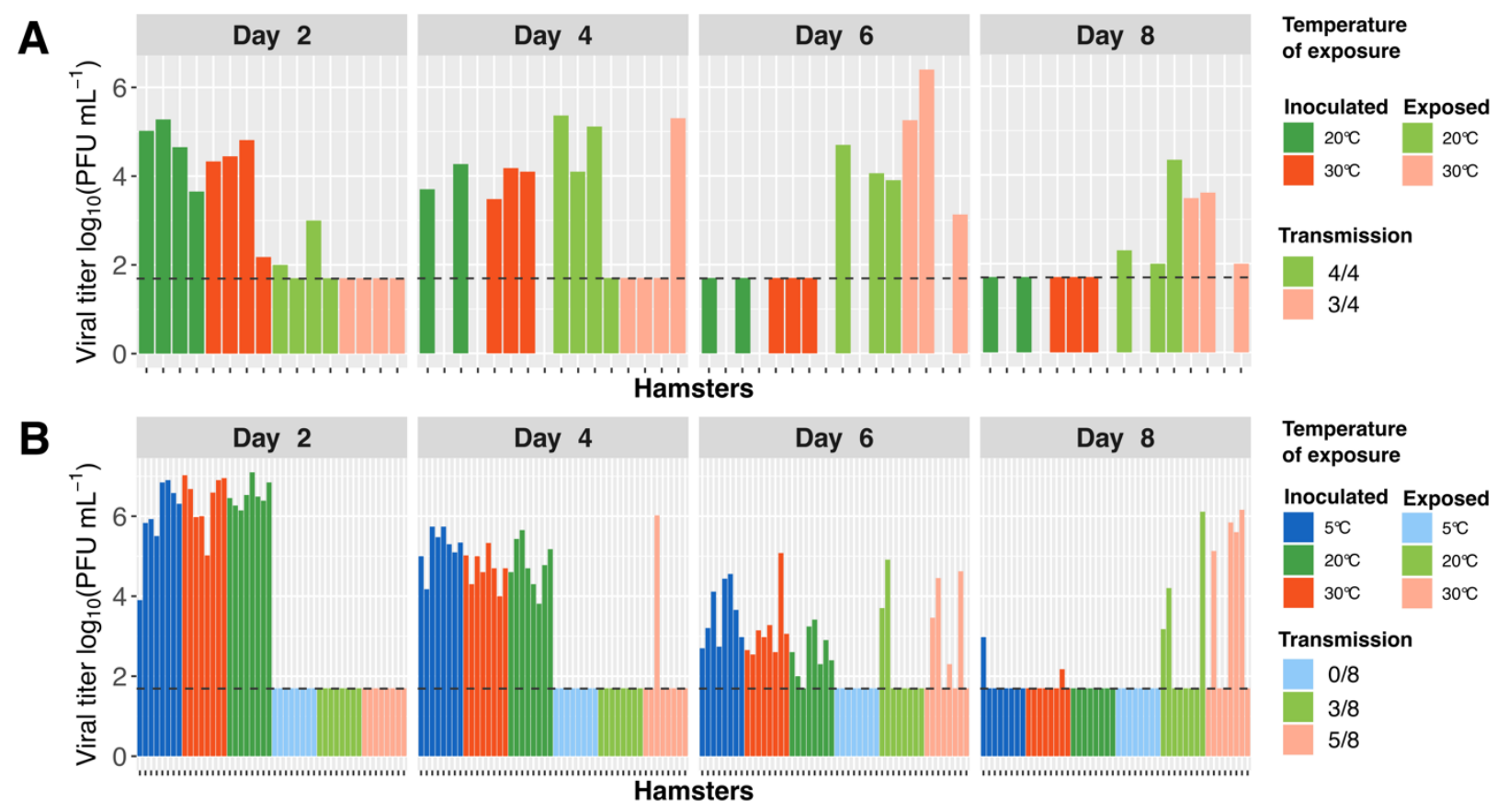

Figure 5. Low temperature does not promote SARS-CoV-2 transmission in hamsters. Viral

226 titers in nasal lavage samples collected from inoculated (dark colors) and exposed (light colors)

227 hamsters are plotted. Facets show results from 2, 4, 6 and 8 days post-inoculation (dpi) with

228 different colors indicating the temperature of exposure. A) Donor hamsters were inoculated with

$2291 \times 10^{4}$ PFU (titered on VeroE6 cells) and contacts were exposed for a period five days under the

230 indicated temperature conditions, beginning at 24 hpi. N=4 transmission pairs. B) Donor animals

231 were inoculated with $1 \times 10^{2}$ PFU (titered on VeroE6 cells) and contacts were exposed for a period

232 of one hour under the indicated temperature conditions, from 16-17 hpi. Data are combined from

233 two independent experiments, giving a total of $n=8$ transmission pairs. Horizontal dashed line

234 indicates limit of detection (50 PFU). Missing data indicate that the animal died or was euthanized

235 mid-way through the experiment. $R H$ was $50 \%$ for all experiments shown. 


\section{Discussion}

240 The COVID-19 pandemic has laid bare the importance of understanding the efficiency and

241 dynamics of respiratory virus transmission. Here we report the results of detailed animal studies

242 designed to quantify the effects of exposure duration, exposure timing and environmental

243 conditions on SARS-CoV-2 transmission. Using a hamster model in which donor and contact

244 animals share air space but are not in direct contact, we find that SARS-CoV-2 transmission is

245 highly efficient, leading to infection of the majority of recipient animals with exposure periods as

246 short as one hour and under a wide range of humidity and temperature conditions. Peak

247 transmission was observed when exposures were carried out between $16 \mathrm{~h}$ and $48 \mathrm{~h}$ after

248 inoculation of donor hamsters, revealing an early and narrow window of opportunity for

249 transmission. This period of infectivity corresponded with high viral titers in the nasal tract,

250 implicating viral load as a major driver of transmission.

252 Substantial evidence has accumulated for pre-symptomatic transmission of SARS-CoV-2 among 253 humans, suggesting that the infectious period begins early after infection (31-34). However, the

254 timing of infection and any subsequent transmission are often difficult to determine in natural 255 settings. Experimental studies allow these parameters to be determined with precision and our 256 data indicate that onward transmission of SARS-CoV-2 occurs readily after only a brief incubation 257 period of $\sim 16 \mathrm{~h}$. However, in translating this information to humans, it is important to note that the 258 course of viral replication observed in inoculated hamsters was abbreviated relative to that in 259 humans. While clinical data suggest that peak viral loads occur 3-4 days after infection $(35,36)$, 260 peak titers were seen in hamsters at $24 \mathrm{hpi}$. This difference of kinetics may relate to initial dose, 261 as inoculation of $1 \times 10^{2}-1 \times 10^{4}$ PFU used here likely exceed a typical natural dose. Indeed, 262 examination of viral titers in recipient animals shows delayed kinetics of replication for brief, early 263 exposures - likely associated with lower initial dose - compared to exposures carried out over an 264 extended period or at the peak of donor viral load. As a result, the period of contagiousness 
265 identified in hamsters may not translate directly to human hosts. However, the observation that

266 the period of contagiousness corresponds to times of high viral load is likely to extend to humans.

268 Our data suggest that temporal changes in the potential for transmission likely stem from changes

269 in viral load. While a direct relationship between viral load and transmission potential is intuitive,

270 the extent to which respiratory virus transmission relies on symptoms and is limited by antiviral

271 responses in the donor individual remain active areas of investigation (37-40). The observation

272 herein that transmission efficiency declines with infectious viral titers both early and late in the

273 course of infection suggests that viral load is a primary determinant of transmission, irrespective

274 of the host processes that influence viral load. These results are consistent with those of a COVID-

27519 cohort study which showed a strong relationship between transmission and viral load,

276 independent of symptoms (41). Viral loads detected in infected individuals vary across several

277 orders of magnitude $(36,42)$; while timing and method of sample collection likely contribute to this

278 disparity, biological variation appears to be high. The link between viral loads and transmission is

279 therefore critical to understand. Our data support the notion that heterogeneity in viral load across

280 individuals is a plausible driver of the extreme transmission heterogeneity observed for SARS-

281 CoV-2 $(31,43)$.

283 Similarities between coronaviruses and influenza viruses in their modes of transmission, particle

284 structure and seasonality suggest that similar factors likely shape the transmission of these

285 pathogens (44). For influenza A virus (IAV), we previously showed that ambient temperature and

286 humidity have a strong impact on transmission in controlled, experimental settings (28-30). Clear

287 correlations between these meteorological variables and population level influenza activity have

288 also been reported $(45,46)$. Thus, seasonal changes in humidity and temperature are likely major

289 drivers of influenza dynamics at the population level. These observations led to our hypothesis

290 that SARS-CoV-2 transmission would be suppressed by high ambient humidity and temperature 
291 conditions. Our data do not validate this hypothesis and instead reveal efficient transmission

292 among hamsters housed in humid or warm environments. Robust transmission under humid

293 conditions is consistent with the U-shaped relationship between $\mathrm{RH}$ and stability that has been

294 reported for multiple enveloped viruses, including SARS-CoV-2 (47-49). In general, however,

295 these results were unexpected based on reports of super-spreading events in cold or dry indoor

296 environments (50-53) and available information on how temperature and $\mathrm{RH}$ modulate viral

297 stability, host susceptibility and aerosol dynamics $(49,54-56)$. The unexpected results may stem

298 from our approach of performing exposures early in the course of infection; transmission success

299 may be more subject to stochastic effects at early times compared to exposures carried out at

300 times when viral load in donors is at peak levels.

302 While circulation of endemic coronaviruses shows a clear seasonal pattern (57-59), increased

303 activity in winter has not been a consistent feature of the COVID-19 pandemic. Influenza

304 pandemics also do not follow the typical seasonality of epidemic influenza but have shown a

305 decline in circulation during summer months $(60,61)$, suggesting the relative influence of

306 seasonal drivers is reduced but not ablated for pandemic influenza. In the case of SARS-CoV-2,

307 a lack of seasonal patterns at this early stage in its circulation may reflect low population immunity,

308 dominance of other epidemiological factors such as population behavior and government

309 interventions (16), or a lack of sensitivity to the seasonal drivers that shape the dynamics of

310 epidemic coronaviruses and seasonal influenza viruses. While our data suggest a lack of

311 sensitivity to humidity and temperature, we caution against over-interpretation of these data given

312 the limitations inherent in our experimental system.

314 A detailed understanding of the host, viral and environmental factors that shape transmission

315 efficiency is of fundamental importance to efforts to elucidate the drivers of SARS-CoV-2

316 dynamics across spatial-temporal scales. This knowledge in turn is invaluable for refining 
317 strategies to interrupt transmission. Our data reveal that the timing of exposure is a potent

318 determinant of transmission potential and point to viral load as the underlying driver of this effect.

320 Methods

\section{$321 \quad$ Virus}

322 SARS-CoV-2/human/USA/GA-83E/2020 was isolated from a clinical sample by culture on VeroE6

323 cells (62). The passage 1 virus stock was aliquoted and stored at $-80^{\circ} \mathrm{C}$. Genomic analysis verified

324 the predominance of full-length genomes and retention of the furin cleavage site in Spike.

325 Sequencing also revealed the presence of the D614G polymorphism in the Spike protein and six

326 nucleotide deletion in ORF 8 (nucleotides 28,090-28,095; amino acids AGSKS to A--ES). Viral

327 titers were determined by plaque assay on VeroE6 cells. The passage 1 virus stock was used for

328 all experiments outlined herein.

$\underline{\text { Cells }}$

331 VeroE6 cells were obtained from ATCC (clone E6, ATCC, \#CRL-1586) and cultured in DMEM 332 (Gibco) supplemented with 10\% fetal bovine serum (Biotechne), MEM nonessential amino acids 333 (Corning) and Normocin (Invivogen). Cells were routinely confirmed to be negative for 334 mycoplasma contamination. These cells were used for viral culture and titration.

\section{Animals}

337 All animal experiments were conducted in accordance with the Guide for the Care and Use of 338 Laboratory Animals of the National Institutes of Health. Studies were conducted under animal 339 biosafety level 3 (ABSL-3) containment and approved by the IACUC of Emory University (protocol 340 PROTO202000055). Animals were humanely euthanized following guidelines approved by the 341 American Veterinary Medical Association (AVMA). Outbred, male, Golden Syrian hamsters of 90$342101 \mathrm{~g}$ body weight were obtained from Charles River Laboratories and singly housed on paper 
343 bedding with access to food and water ad libitum. Prior to inoculation, nasal lavage and

344 euthanasia, hamsters were sedated with ketamine $(120 \mathrm{mg} / \mathrm{kg})$ - xylazine $(4 \mathrm{mg} / \mathrm{kg})$ administered

345 intraperitoneally. Xylazine was reversed with $1 \mathrm{mg} / \mathrm{kg}$ of atipamezole administered

346 intraperitoneally. Animal health was monitored daily through visual observation and determination

347 of body weight.

\section{Inoculation}

350 Virus was diluted serially in PBS to achieve the desired dose and then sedated hamsters were

351 inoculated intranasally with a 100 ul, applied dropwise to both nares with the animal in dorsal

352 recumbency. Doses ranged from $1 \times 10^{2}$ PFU to $1 \times 10^{4}$ PFU (titered on VeroE6 cells), as indicated

353 in figure legends.

$355 \quad$ Nasal lavage

356 Virus was sampled from the upper respiratory tract by nasal lavage. Sedated hamsters were

357 placed in ventral recumbency with nose suspended above an open Petri dish. A total volume of 358400 ul PBS was applied to the nares using a micropipette and allowed to drop back into the dish.

359 An additional volume of 200 ul PBS was used to wash the dish. Fluid in the dish was collected, 360 aliquoted and stored at $-80^{\circ} \mathrm{C}$ prior to determination of viral titers by plaque assay.

\section{Exposure of naïve hamsters to inoculated hamsters}

363 Exposures were carried out in rodent cages modified through the addition of a double-walled 364 porous barrier, which divided the cage in two. A single hamster was placed on either side of the 365 barrier. The barrier reached from wall-to-wall and floor-to-lid and comprised two stainless-steel 366 sheets placed $1 \mathrm{~cm}$ apart, with $0.5 \mathrm{~cm}$ perforations arrayed across each sheet. Each side of the 367 cage was supplied with food and water. The cage was enclosed with a filter top. 
368 For all exposures, cages were placed within a Caron 6040 environmental chamber. These 369 chambers allow tight control of humidity and temperature conditions. To achieve uniformity of 370 these conditions throughout the chamber, air flow rates are relatively high, at $13000 \mathrm{~L} / \mathrm{min}$.

371 Environmental conditions within the chamber and within the rodent cages (with hamsters present)

372 were verified using a Temperature/Humidity WIFI Data Logger (Traceable Products; Webster,

373 Texas). Desired conditions were readily met within the hamster cages. After opening the chamber

374 door to place cages, recovery time varied from 10 to 60 minutes, with dry (20 or $30 \% \mathrm{RH}$ )

375 conditions requiring the longest recovery times. To allow testing of different $\mathrm{RH}$ conditions, it was

376 therefore important to place the animals in the chambers at an early time point after inoculation

377 of donors (14 hpi) such that chamber equilibration was achieved prior to the start of the infectious

378 period (16 hpi).

379 Inoculated donor animals were singly housed within environmental chambers shortly after

380 inoculation. One naïve recipient was introduced on the opposite side of each exposure cage at

$38114 \mathrm{~h}-6 \mathrm{dpi}$, as indicated in each figure legend. Exposures were carried out for durations ranging

382 from $1 \mathrm{~h}$ to $5 \mathrm{~d}$. Where exposures exceeded $24 \mathrm{~h}$, animals were removed from the chambers on

383 a daily basis for determination of body weight and, on a subset of days, nasal lavage. To avoid 384 spurious transmission, care was taken during animal handling. Gloves were changed and 385 biosafety cabinet and weighing container were disinfected between animals.

\section{$387 \quad$ Data analysis}

388 Data analysis was done using RStudio 1.3.959 and Prism version 6.0.7. Plots were aesthetically 389 modified using Inkscape 1.0.

\section{Acknowledgements}

392 We thank Hui Tao and Shamika Danzy for technical assistance and the Emory University Division 393 of Animal Resources for their support with animal care, cage construction and logistical 
challenges. This work was funded by the National Institute of Allergy and Infectious Disease

through the Centers of Excellence for Influenza Research and Surveillance (CEIRS) contract no.

HHSN272201400004C. GKD is supported by F31 Al 50114.

\section{References}

399 1. Flaxman S, Mishra S, Gandy A, Unwin HJT, Mellan TA, Coupland H, Whittaker C, Zhu H, Berah T, Eaton JW, Monod M, Perez-Guzman PN, Schmit N, Cilloni L, Ainslie KEC, Baguelin M, Boonyasiri A, Boyd O, Cattarino L, Cooper LV, Cucunubá Z, CuomoDannenburg G, Dighe A, Djaafara B, Dorigatti I, van Elsland SL, FitzJohn RG, Gaythorpe KAM, Geidelberg L, Grassly NC, Green WD, Hallett T, Hamlet A, Hinsley W, Jeffrey B, Knock E, Laydon DJ, Nedjati-Gilani G, Nouvellet P, Parag KV, Siveroni I, Thompson HA, Verity R, Volz E, Walters CE, Wang H, Wang Y, Watson OJ, Winskill P, Xi X, et al. 2020. Estimating the effects of non-pharmaceutical interventions on COVID-19 in Europe. Nature 584:257-261.

2. Lai S, Ruktanonchai NW, Zhou L, Prosper O, Luo W, Floyd JR, Wesolowski A, Santillana M, Zhang C, Du X, Yu H, Tatem AJ. 2020. Effect of non-pharmaceutical interventions to contain COVID-19 in China. Nature 585:410-413.

3. Ferguson N, Laydon D, Nedjati Gilani G, Imai N, Ainslie K, Baguelin M, Bhatia S, Boonyasiri A, Cucunuba Perez Z, Cuomo-Dannenburg G. 2020. Report 9: Impact of nonpharmaceutical interventions (NPIs) to reduce COVID19 mortality and healthcare demand.

4. $\quad \mathrm{Ng} \mathrm{Y,} \mathrm{Li} \mathrm{Z,} \mathrm{Chua} \mathrm{YX,} \mathrm{Chaw} \mathrm{WL,} \mathrm{Zhao} \mathrm{Z,} \mathrm{Er} \mathrm{B,} \mathrm{Pung} \mathrm{R,} \mathrm{Chiew} \mathrm{CJ,} \mathrm{Lye} \mathrm{DC,} \mathrm{Heng} \mathrm{D,} \mathrm{Lee}$ VJ. 2020. Evaluation of the Effectiveness of Surveillance and Containment Measures for the First 100 Patients with COVID-19 in Singapore - January 2-February 29, 2020. MMWR Morb Mortal Wkly Rep 69:307-311.

5. $\quad \mathrm{Ng}$ OT, Marimuthu K, Koh V, Pang J, Linn KZ, Sun J, De Wang L, Chia WN, Tiu C, Chan M, Ling LM, Vasoo S, Abdad MY, Chia PY, Lee TH, Lin RJ, Sadarangani SP, Chen MI, Said Z, Kurupatham L, Pung R, Wang LF, Cook AR, Leo YS, Lee VJ. 2021. SARS-CoV2 seroprevalence and transmission risk factors among high-risk close contacts: a retrospective cohort study. Lancet Infect Dis 21:333-343.

6. Quilty BJ, Clifford S, Hellewell J, Russell TW, Kucharski AJ, Flasche S, Edmunds WJ, Centre for the Mathematical Modelling of Infectious Diseases C-wg. 2021. Quarantine and testing strategies in contact tracing for SARS-CoV-2: a modelling study. Lancet Public Health 6:e175-e183.

7. Ashcroft P, Lehtinen S, Angst DC, Low N, Bonhoeffer S. 2021. Quantifying the impact of quarantine duration on COVID-19 transmission. Elife 10.

8. Ma Y, Pei S, Shaman J, Dubrow R, Chen K. 2021. Role of meteorological factors in the transmission of SARS-CoV-2 in the United States. Nature Communications 12:3602.

9. Choi Y-W, Tuel A, Eltahir EAB. 2021. On the Environmental Determinants of COVID-19 Seasonality. GeoHealth 5:e2021GH000413-e2021GH000413.

10. Smith TP, Flaxman S, Gallinat AS, Kinosian SP, Stemkovski M, Unwin HJT, Watson OJ, Whittaker C, Cattarino L, Dorigatti I, Tristem M, Pearse WD. 2021. Temperature and population density influence SARS-CoV-2 transmission in the absence of nonpharmaceutical interventions. Proceedings of the National Academy of Sciences 118:e2019284118. 
11. Smith TP, Flaxman S, Gallinat AS, Kinosian SP, Stemkovski M, Unwin HJT, Watson OJ, Whittaker C, Cattarino L, Dorigatti I, Tristem M, Pearse WD. 2021. Temperature and population density influence SARS-CoV-2 transmission in the absence of nonpharmaceutical interventions. Proc Natl Acad Sci U S A 118.

12. Landier J, Paireau J, Rebaudet S, Legendre E, Lehot L, Fontanet A, Cauchemez S, Gaudart J. 2021. Cold and dry winter conditions are associated with greater SARS-CoV2 transmission at regional level in western countries during the first epidemic wave. Sci Rep 11:12756.

13. Yao Y, Pan J, Liu Z, Meng X, Wang W, Kan H, Wang W. 2020. No association of COVID19 transmission with temperature or UV radiation in Chinese cities. Eur Respir J 55.

14. Juni P, Rothenbuhler M, Bobos P, Thorpe KE, da Costa BR, Fisman DN, Slutsky AS, Gesink D. 2020. Impact of climate and public health interventions on the COVID-19 pandemic: a prospective cohort study. CMAJ 192:E566-E573.

15. Yuan J, Wu Y, Jing W, Liu J, Du M, Wang Y, Liu M. 2021. Association between meteorological factors and daily new cases of COVID-19 in 188 countries: A time series analysis. Sci Total Environ 780:146538.

16. Sera F, Armstrong B, Abbott S, Meakin S, O'Reilly K, von Borries R, Schneider R, Roye D, Hashizume M, Pascal M, Tobias A, Vicedo-Cabrera AM, Network MCCCR, Group CCW, Gasparrini A, Lowe R. 2021. A cross-sectional analysis of meteorological factors and SARS-CoV-2 transmission in 409 cities across 26 countries. Nat Commun 12:5968.

17. Mecenas P, Bastos R, Vallinoto ACR, Normando D. 2020. Effects of temperature and humidity on the spread of COVID-19: A systematic review. PLoS One 15:e0238339.

18. Sia SF, Yan L-M, Chin AW, Fung K, Poon LL, Nicholls JM, Peiris M, Yen H-L. Pre-print. Pathogenesis and transmission of SARS-CoV-2 virus in golden Syrian hamsters. doi:10.21203/rs.3.rs-20774/v1.

19. Imai M, Iwatsuki-Horimoto K, Hatta M, Loeber S, Halfmann PJ, Nakajima N, Watanabe T, Ujie M, Takahashi K, Ito M, Yamada S, Fan S, Chiba S, Kuroda M, Guan L, Takada K, Armbrust T, Balogh A, Furusawa Y, Okuda M, Ueki H, Yasuhara A, Sakai-Tagawa Y, Lopes TJS, Kiso M, Yamayoshi S, Kinoshita N, Ohmagari N, Hattori SI, Takeda M, Mitsuya H, Krammer F, Suzuki T, Kawaoka Y. 2020. Syrian hamsters as a small animal model for SARS-CoV-2 infection and countermeasure development. Proc Natl Acad Sci U S A 117:16587-16595.

20. Lee CY, Lowen AC. 2021. Animal models for SARS-CoV-2. Curr Opin Virol 48:73-81.

21. Horiuchi S, Oishi K, Carrau L, Frere J, Moller R, Panis M, tenOever BR. 2021. Immune memory from SARS-CoV-2 infection in hamsters provides variant-independent protection but still allows virus transmission. Sci Immunol doi:10.1126/sciimmunol.abm3131:eabm3131.

22. Abdelnabi R, Foo CS, Kaptein SJF, Zhang X, Do TND, Langendries L, Vangeel L, Breuer J, Pang J, Williams R, Vergote V, Heylen E, Leyssen P, Dallmeier K, Coelmont L, Chatterjee AK, Mols R, Augustijns P, De Jonghe S, Jochmans D, Weynand B, Neyts J. 2021. The combined treatment of Molnupiravir and Favipiravir results in a potentiation of antiviral efficacy in a SARS-CoV-2 hamster infection model. EBioMedicine 72:103595.

23. Zhou B, Thao TTN, Hoffmann D, Taddeo A, Ebert N, Labroussaa F, Pohlmann A, King J, Steiner S, Kelly JN, Portmann J, Halwe NJ, Ulrich L, Trueb BS, Fan X, Hoffmann B, Wang L, Thomann L, Lin X, Stalder H, Pozzi B, de Brot S, Jiang N, Cui D, Hossain J, Wilson MM, Keller MW, Stark TJ, Barnes JR, Dijkman R, Jores J, Benarafa C, Wentworth DE, Thiel V, Beer M. 2021. SARS-CoV-2 spike D614G change enhances replication and transmission. Nature 592:122-127.

24. Hou YJ, Chiba S, Halfmann P, Ehre C, Kuroda M, Dinnon KH, 3rd, Leist SR, Schafer A, Nakajima N, Takahashi K, Lee RE, Mascenik TM, Graham R, Edwards CE, Tse LV, Okuda 489 K, Markmann AJ, Bartelt L, de Silva A, Margolis DM, Boucher RC, Randell SH, Suzuki T, 
Gralinski LE, Kawaoka Y, Baric RS. 2020. SARS-CoV-2 D614G variant exhibits efficient replication ex vivo and transmission in vivo. Science 370:1464-1468.

25. Plante JA, Liu Y, Liu J, Xia H, Johnson BA, Lokugamage KG, Zhang X, Muruato AE, Zou J, Fontes-Garfias CR, Mirchandani D, Scharton D, Bilello JP, Ku Z, An Z, Kalveram B, Freiberg AN, Menachery VD, Xie X, Plante KS, Weaver SC, Shi PY. 2021. Spike mutation D614G alters SARS-CoV-2 fitness. Nature 592:116-121.

26. Valcarcel J, Ortin J. 1989. Phenotypic hiding: the carryover of mutations in RNA viruses as shown by detection of mar mutants in influenza virus. J Virol 63:4107-9.

27. DaPalma T, Doonan BP, Trager NM, Kasman LM. 2010. A systematic approach to virusvirus interactions. Virus Res 149:1-9.

28. Lowen AC, Mubareka S, Steel J, Palese P. 2007. Influenza virus transmission is dependent on relative humidity and temperature. PLoS Pathog 3:1470-6.

29. Lowen AC, Steel J, Mubareka S, Palese P. 2008. High temperature (30 degrees C) blocks aerosol but not contact transmission of influenza virus. J Virol 82:5650-2.

30. Steel J, Palese P, Lowen AC. 2011. Transmission of a 2009 pandemic influenza virus shows a sensitivity to temperature and humidity similar to that of an $\mathrm{H} 3 \mathrm{~N} 2$ seasonal strain. J Virol 85:1400-2.

31. Adam DC, Wu P, Wong JY, Lau EHY, Tsang TK, Cauchemez S, Leung GM, Cowling BJ. 2020. Clustering and superspreading potential of SARS-CoV-2 infections in Hong Kong. Nat Med 26:1714-1719.

32. Huang L, Zhang X, Zhang X, Wei Z, Zhang L, Xu J, Liang P, Xu Y, Zhang C, Xu A. 2020. Rapid asymptomatic transmission of COVID-19 during the incubation period demonstrating strong infectivity in a cluster of youngsters aged 16-23 years outside Wuhan and characteristics of young patients with COVID-19: A prospective contacttracing study. J Infect 80:e1-e13.

33. Johansson MA, Quandelacy TM, Kada S, Prasad PV, Steele M, Brooks JT, Slayton RB, Biggerstaff M, Butler JC. 2021. SARS-CoV-2 Transmission From People Without COVID19 Symptoms. JAMA Netw Open 4:e2035057.

34. Hart WS, Maini PK, Thompson RN. 2021. High infectiousness immediately before COVID19 symptom onset highlights the importance of continued contact tracing. Elife 10.

35. Jones TC, Biele G, Muhlemann B, Veith T, Schneider J, Beheim-Schwarzbach J, Bleicker T, Tesch J, Schmidt ML, Sander LE, Kurth F, Menzel P, Schwarzer R, Zuchowski M, Hofmann J, Krumbholz A, Stein A, Edelmann A, Corman VM, Drosten C. 2021. Estimating infectiousness throughout SARS-CoV-2 infection course. Science 373.

36. Ke R, Martinez PP, Smith RL, Gibson LL, Mirza A, Conte M, Gallagher N, Luo CH, Jarrett J, Conte A, Liu T, Farjo M, Walden KKO, Rendon G, Fields CJ, Wang L, Fredrickson R, Edmonson DC, Baughman ME, Chiu KK, Choi H, Scardina KR, Bradley S, Gloss SL, Reinhart C, Yedetore J, Quicksall J, Owens AN, Broach J, Barton B, Lazar P, Heetderks WJ, Robinson ML, Mostafa HH, Manabe YC, Pekosz A, McManus DD, Brooke CB. 2021. Daily sampling of early SARS-CoV-2 infection reveals substantial heterogeneity in infectiousness. medRxiv doi:10.1101/2021.07.12.21260208.

37. Lau LL, Cowling BJ, Fang VJ, Chan KH, Lau EH, Lipsitch M, Cheng CK, Houck PM, Uyeki TM, Peiris JS, Leung GM. 2010. Viral shedding and clinical illness in naturally acquired influenza virus infections. J Infect Dis 201:1509-16.

38. Tsang TK, Fang VJ, Chan KH, Ip DK, Leung GM, Peiris JS, Cowling BJ, Cauchemez S. 2016. Individual Correlates of Infectivity of Influenza A Virus Infections in Households. PLoS One 11:e0154418.

39. Danzy S, Lowen AC, Steel J. 2021. A quantitative approach to assess influenza A virus fitness and transmission in guinea pigs. J Virol doi:10.1128/JVI.02320-20.

40. Harrison AG, Lin T, Wang P. 2020. Mechanisms of SARS-CoV-2 Transmission and Pathogenesis. Trends Immunol 41:1100-1115. 
582

583

584

585

586

587

588

589

590

41. Marks $M$, Millat-Martinez $P$, Ouchi D, Roberts $\mathrm{CH}$, Alemany A, Corbacho-Monne $\mathrm{M}$, Ubals M, Tobias A, Tebe C, Ballana E, Bassat Q, Baro B, Vall-Mayans M, C GB, Prat N, Ara J, Clotet B, Mitja O. 2021. Transmission of COVID-19 in 282 clusters in Catalonia, Spain: a cohort study. Lancet Infect Dis 21:629-636.

42. Jones TC, Biele G, Muhlemann B, Veith T, Schneider J, Beheim-Schwarzbach J, Bleicker T, Tesch J, Schmidt ML, Sander LE, Kurth F, Menzel P, Schwarzer R, Zuchowski M, Hofmann J, Krumbholz A, Stein A, Edelmann A, Corman VM, Drosten C. 2021. Estimating infectiousness throughout SARS-CoV-2 infection course. Science doi:10.1126/science.abi5273.

43. Lakdawala SS, Menachery VD. 2021. Catch me if you can: superspreading of COVID-19. Trends Microbiol doi:10.1016/j.tim.2021.05.002.

44. Moriyama M, Hugentobler WJ, Iwasaki A. 2020. Seasonality of Respiratory Viral Infections. Annu Rev Virol doi:10.1146/annurev-virology-012420-022445.

45. Shaman J, Goldstein E, Lipsitch M. 2011. Absolute humidity and pandemic versus epidemic influenza. Am J Epidemiol 173:127-35.

46. Shaman J, Pitzer VE, Viboud C, Grenfell BT, Lipsitch M. 2010. Absolute humidity and the seasonal onset of influenza in the continental United States. PLoS Biol 8:e1000316.

47. Prussin AJ, 2nd, Schwake DO, Lin K, Gallagher DL, Buttling L, Marr LC. 2018. Survival of the Enveloped Virus Phi6 in Droplets as a Function of Relative Humidity, Absolute Humidity, and Temperature. Appl Environ Microbiol 84.

48. Schaffer FL, Soergel ME, Straube DC. 1976. Survival of airborne influenza virus: effects of propagating host, relative humidity, and composition of spray fluids. Arch Virol 51:26373.

49. Morris DH, Yinda KC, Gamble A, Rossine FW, Huang Q, Bushmaker T, Fischer RJ, Matson MJ, Van Doremalen N, Vikesland PJ, Marr LC, Munster VJ, Lloyd-Smith JO. 2021. Mechanistic theory predicts the effects of temperature and humidity on inactivation of SARS-CoV-2 and other enveloped viruses. Elife 10.

50. Dyal JW, Grant MP, Broadwater K, Bjork A, Waltenburg MA, Gibbins JD, Hale C, Silver M, Fischer M, Steinberg J, Basler CA, Jacobs JR, Kennedy ED, Tomasi S, Trout D, Hornsby-Myers J, Oussayef NL, Delaney LJ, Patel K, Shetty V, Kline KE, Schroeder B, Herlihy RK, House J, Jervis R, Clayton JL, Ortbahn D, Austin C, Berl E, Moore Z, Buss BF, Stover D, Westergaard R, Pray I, DeBolt M, Person A, Gabel J, Kittle TS, Hendren P, Rhea C, Holsinger C, Dunn J, Turabelidze G, Ahmed FS, deFijter S, Pedati CS, Rattay K, Smith EE, Luna-Pinto C, Cooley LA, et al. 2020. COVID-19 Among Workers in Meat and Poultry Processing Facilities - 19 States, April 2020. MMWR Morb Mortal Wkly Rep 69.

51. Gunther T, Czech-Sioli M, Indenbirken D, Robitaille A, Tenhaken P, Exner M, Ottinger M, Fischer N, Grundhoff A, Brinkmann MM. 2020. SARS-CoV-2 outbreak investigation in a German meat processing plant. EMBO Mol Med 12:e13296.

52. Atrubin D, Wiese M, Bohinc B. 2020. An Outbreak of COVID-19 Associated with a Recreational Hockey Game - Florida, June 2020. MMWR Morb Mortal Wkly Rep 69:14921493.

53. Khanh NC, Thai PQ, Quach HL, Thi NH, Dinh PC, Duong TN, Mai LTQ, Nghia ND, Tu TA, Quang N, Quang TD, Nguyen TT, Vogt F, Anh DD. 2020. Transmission of SARS-CoV 2 During Long-Haul Flight. Emerg Infect Dis 26:2617-2624.

54. Kormuth KA, Lin K, Prussin AJ, 2nd, Vejerano EP, Tiwari AJ, Cox SS, Myerburg MM, Lakdawala SS, Marr LC. 2018. Influenza Virus Infectivity Is Retained in Aerosols and Droplets Independent of Relative Humidity. J Infect Dis 218:739-747.

55. Kudo E, Song E, Yockey LJ, Rakib T, Wong PW, Homer RJ, Iwasaki A. 2019. Low ambient humidity impairs barrier function and innate resistance against influenza infection. Proc Natl Acad Sci U S A 116:10905-10910. 
56. Marr LC, Tang JW, Van Mullekom J, Lakdawala SS. 2019. Mechanistic insights into the effect of humidity on airborne influenza virus survival, transmission and incidence. J R Soc Interface 16:20180298.

57. Li Y, Wang X, Nair H. 2020. Global Seasonality of Human Seasonal Coronaviruses: A Clue for Postpandemic Circulating Season of Severe Acute Respiratory Syndrome Coronavirus 2? The Journal of Infectious Diseases 222:1090-1097.

58. Monto AS, DeJonge PM, Callear AP, Bazzi LA, Capriola SB, Malosh RE, Martin ET, Petrie JG. 2020. Coronavirus Occurrence and Transmission Over 8 Years in the HIVE Cohort of Households in Michigan. The Journal of Infectious Diseases 222:9-16.

59. Li Y, Wang X, Nair H. 2020. Global Seasonality of Human Seasonal Coronaviruses: A Clue for Postpandemic Circulating Season of Severe Acute Respiratory Syndrome Coronavirus 2? J Infect Dis 222:1090-1097.

60. Fox SJ, Miller JC, Meyers LA. 2017. Seasonality in risk of pandemic influenza emergence. PLOS Computational Biology 13:e1005749.

61. Andreasen V, Viboud C, Simonsen L. 2008. Epidemiologic characterization of the 1918 influenza pandemic summer wave in Copenhagen: implications for pandemic control strategies. The Journal of infectious diseases 197:270-278.

609

62. Edara VV, Hudson WH, Xie X, Ahmed R, Suthar MS. 2021. Neutralizing Antibodies Against SARS-CoV-2 Variants After Infection and Vaccination. JAMA 325:1896-1898. 